\title{
Chagas disease in Mexico: an analysis of geographical distribution during the past 76 years - A Review Alejandro Cruz-Reyes $/{ }^{+}$, José Miguel Pickering-López
}

\author{
Instituto de Biología, Universidad Nacional Autónoma de México, Ap. Postal 70-153, C. P. 04510, México, D. F. México
}

Literature from 1928 through 2004 was compiled from different document sources published in Mexico or elsewhere. From these 907 publications, we found 19 different topics of Chagas disease study in Mexico. The publications were arranged by decade and also by state. This information was used to construct maps describing the distribution of Chagas disease according to different criteria: the disease, vectors, reservoirs, and strains. One of the major problems confronting study of this zoonotic disease is the great biodiversity of the vector species; there are 30 different species, with at least 10 playing a major role in human infection. The high variability of climates and biogeographic regions further complicate study and understanding of the dynamics of this disease in each region of the country. We used a desktop Genetic Algorithm for Rule-Set Prediction procedure to provide ecological models of organism niches, offering improved flexibility for choosing predictive environmental and ecological data. This approach may help to identify regions at risk of disease, plan vector-control programs, and explore parasitic reservoir association. With this collected information, we have constructed a data base: CHAGMEX, available online in html format.

Key words: American trypanosomiasis - Chagas disease - Trypanosoma cruzi - epidemiology - triatomines - Mexico

Several bibliographic reviews of Chagas disease (Olivier et al. 1972) have been published, but none have focused specifically on an individual country. The Mexican government and academic agencies have supported research on Chagas disease, however, even though at least one human case of Chagas disease has been reported in each of the each of the 31 states and the Federal District (the capital city), the Mexican government and academic agencies have not yet presented data on this disease in Mexico. In Mexico, the biodiversity of vectors is quite abundant. Both wild and domestic reservoirs are also numerous. From climatologic and orographic points of view, Mexico has a great variety of habitats providing natural conditions for transmission, along with many rural regions populated by persons of low socio-economic status. Given the increasing rate of human infection by blood transfusion and the prodigious number of papers on genetics and molecular biology within the national and international literature related to Mexico, we decided to investigate what is known about Chagas disease in Mexico and analyze several parameters of this literature (SalazarSchetino et al. 1988, Guzmán-Bracho 2002).

American trypanosomiasis in Mexico provides a suitable backdrop to demonstrate how Geographical Information Systems (GIS) can be employed to understand the connection between environment, ecology, and culture for a vector-borne infection (Johnson 1999, Peterson et al. 2002). This paper presents the results of an extensive survey of the literature on Chagas disease in Mexico and

+Corresponding author: acr@ibiologia.unam.mx Received 12 May 2006

Accepted 29 May 2006 shows how these previous studies can be used to create a current spatial understanding of the extent of the infection throughout the country (Prothero \& Davenport 1986).

The subject of this report is of particular importance as, despite the hundreds of scientific articles considering this disease either directly or indirectly in the country, it has only recently been officially acknowledged (Norma Oficial Mexicana 2001). This has had the combined effect of allowing the disease to reach endemic proportions in some areas, to be spread to new geographic environments, and even to move into new environmental niches because of dissemination via blood transfusion (Rangel et al. 1998, Monteón-Padilla et al. 1999, Reyes et al. 2002). The success of any mitigation strategy is reliant upon an understanding of the different geographies involved, more specifically where the disease is found and what environmental, ecological, and anthropological factors combine to allow the disease to flourish. In this way, limited resources can be effectively targeted to areas where the greatest impact can be made.

To build these maps we have to look for the geographic coordinates of the localities reported in each paper. In general, we found that the information was divided into four major topics and subdivided into 19 subjects:

The disease itself: counting all human cases that have been reported from serological cases, including those from blood bank transfusion and clinical studies.

Vectors: including medical entomological information, such as identification of the species, developmental stage, Trypanosoma cruzi and T. cruzi-like infections, prevalence of infection, location, etc.

Reservoirs: including domestic, wild or synanthropic, as well as the presence of the parasite in host tissues.

Strains: isolation and characterization. 


\section{Objectives}

The purpose of this study was to extract information from over 907 published articles dating back to 1928 in order to create a universally accessible database. One impetus for this data collection strategy was the general lack of communication between different research teams concerning Chagas disease in Mexico; entomologists might not be familiar with the work of zoologists, who in turn, might not be cognizant of the public health literature, while molecular biologists may be unfamiliar with the role of wild reservoirs. The centralization of published information to an online access point will allow these scientific teams to gain an appreciation of other related research, to create linkages between these teams, and most importantly for GIS applications, to provide a geographic overview of the extent of the disease throughout Mexico.

\section{MATERIALS AND METHODS}

From the available literature, we have organized a standard-format database allowing for queries on the spatial locations of clinical cases and human serological prevalence, vectors (including infected and non-infected), wild and domestic reservoirs, and other extracted information. These data, when exported to a GIS, facilitate the creation of disease density and distribution maps.

CHAGMEX, originally an Access ${ }^{\circledR}$ database (Microsoft Corporation, Redmond, Washington, US), was constructed to organize and manage the collection of papers. This database was translated on the Internet, using PostgreSQL and JAVA technology. Information pertinent to the study of Chagas disease in Mexico was categorized into four major subject areas in the database. In order of descending proportion, the current database consists of 907 publications, including scientific articles, technical reports, conference abstracts, conference proceedings, and theses/dissertations.

Extreme care was taken in cross-validating whether the information contained in each paper was unique and not duplicated elsewhere. For example, if a work from a thesis/dissertation appeared as a conference abstract and also within a refereed journal article, the cases or other events were considered only once; however, each paper or report was counted as a record in the database

\section{RESULTS}

The distribution by decade of published papers and reports is presented in Fig. 1. Nine different types of publications were considered for inclusion in the database (Fig. 2). We categorized the Chagas disease research carried out in Mexico into 19 different subjects (Fig. 3). Research on Chagas disease has been performed in every state of the Mexican Republic; the number of publications by state is shown in Fig. 4. The total number of reported human cases in the literature is 16,979 and the distribution by state is shown on Table I and Figs 5 and 6 . Obviously, this number is an under representation of the true extent of human T. cruzi infection and typical disease, because there are both undiagnosed and unreported cases There is also a degree of uncertainty surrounding these data, as in many instances the human cases have

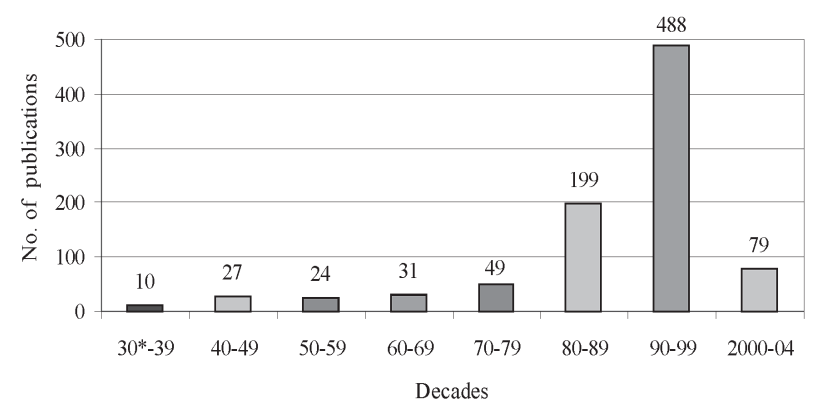

Fig.1: number of publications on different topics of Chagas disease in Mexico by decade, 1928-2004.

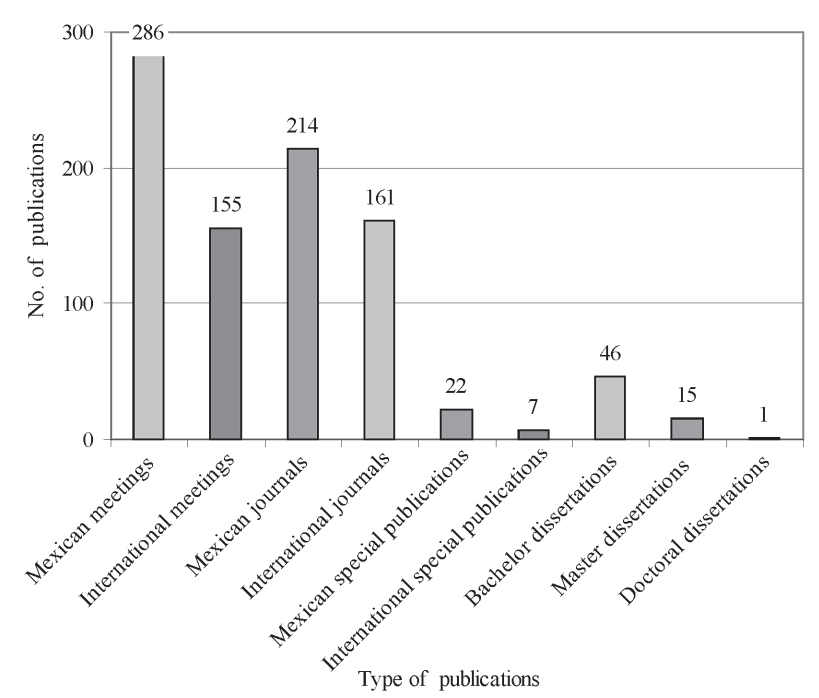

Fig. 2: the nine different types of publications of Chagas' disease research in Mexico, reported from 1928 to 2004.

been extracted from seroepidemiological surveys that were reported by different authors who may have used differing methods and verification techniques. Even so, every state in Mexico had at least twelve reported cases over this time period, with Jalisco recording the highest number, 3236 cases.

An online user can navigate through all of the extracted information and query the database by author, type of publication, subject, and state.The geographic extraction allows for mapping and spatial analyses within a GIS environment. For example, a typical query might be run on a topic, such as "serology", author's name, reference cited, year of publication, the Mexican state(s) of the study, and/or the source type (reviewed article, etc.). Such a query results in a typical extraction of identify all serological papers based on data collected from a specific state in Mexico between 1980 and 1990. Similar queries were used to create figures showing the chronological progression of the published research.

In addition, other attribute information is contained in each topic field. For human cases, the age and sex of the patient, classification of the disease by clinical manifesta- 


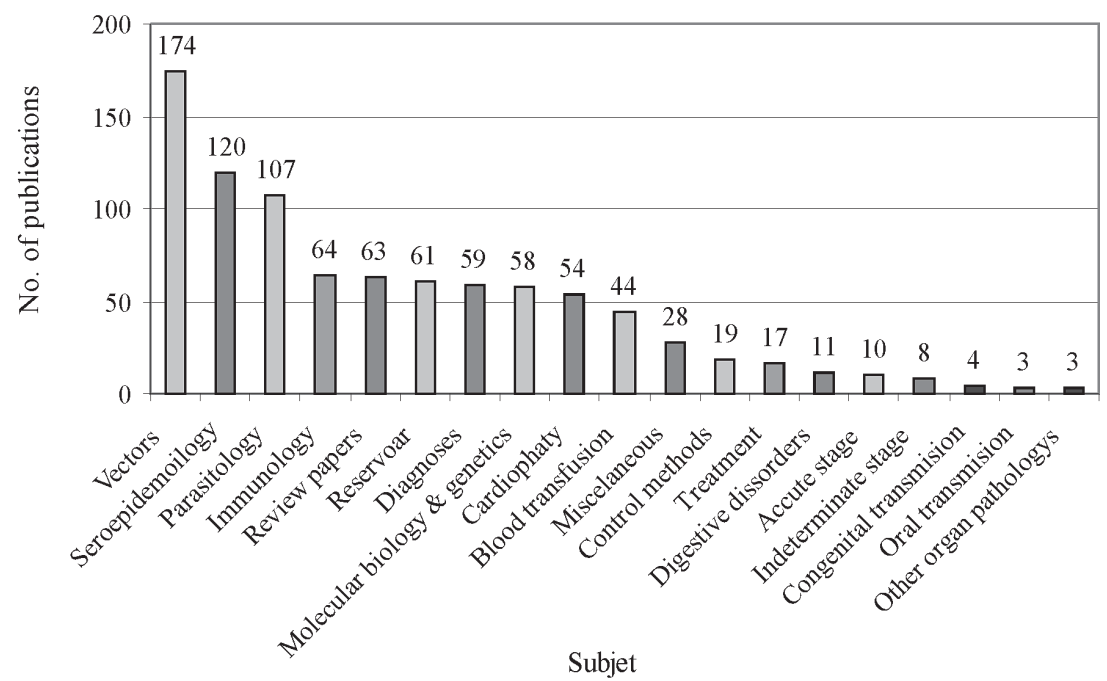

Fig. 3: the 19 subjects into which the information on Chagas disease in Mexico was classified, 1928-2004.

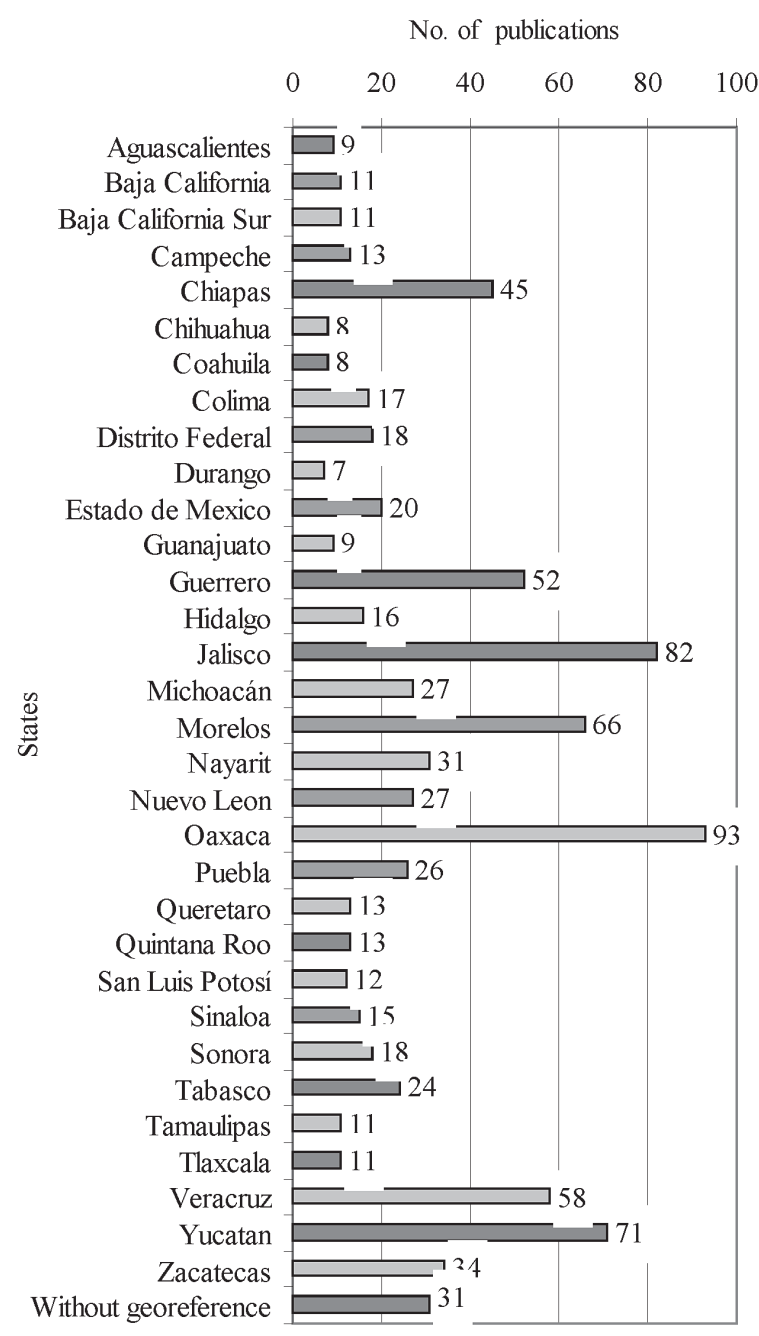

Fig. 4: number of publications containing information about Chagas diseases from each of the 31 states and Federal District of Mexico, 1928-2004.
TABLE I

Total human cases reported in the literature by serological surveys, clinical manifestations, and blood bank reports

\begin{tabular}{lrrr}
\hline State & Sample & Cases & Prevalence $(\%)$ \\
\hline Aguascalientes & 1527 & 28 & 1.83 \\
Baja California & 1619 & 45 & 2.78 \\
Baja California Sur & 2018 & 21 & 1.04 \\
Campeche & 1536 & 24 & 1.56 \\
Chiapas & 7912 & 1009 & 12.75 \\
Chihuahua & 3351 & 15 & 0.45 \\
Coahuila & 1976 & 12 & 0.61 \\
Colima & 1917 & 22 & 1.15 \\
Distrito Federal & 26.213 & 983 & 3.75 \\
Durango & 2065 & 45 & 2.18 \\
Estado de Mexico & 2856 & 18 & 0.63 \\
Guanajuato & 3168 & 26 & 0.82 \\
Guerrero & 9621 & 1090 & 11.33 \\
Hidalgo & 3591 & 222 & 6.18 \\
Jalisco & 26.732 & 3236 & 12.11 \\
Michoacán & 2265 & 50 & 2.21 \\
Morelos & 8787 & 1005 & 11.44 \\
Nayarit & 1994 & 243 & 12.19 \\
Nuevo Leon & 4178 & 81 & 1.94 \\
Oaxaca & 12.624 & 2234 & 17.70 \\
Puebla & 12.970 & 460 & 3.55 \\
Queretaro & 2412 & 458 & 18.99 \\
Quintana Roo & 1575 & 38 & 2.41 \\
San Luis Potosí & 2161 & 56 & 2.59 \\
Sinaloa & 2865 & 160 & 5.58 \\
Sonora & 2280 & 37 & 1.62 \\
Tabasco & 5315 & 200 & 3.76 \\
Tamaulipas & 2022 & 34 & 1.68 \\
Tlaxcala & 1428 & 19 & 1.33 \\
Veracruz & 66.679 & 1932 & 5.74 \\
Yucatan & 212 & 3.17 \\
Zacatecas & 146 & 5.62 \\
Without georeference & 86.692 & 2818 & 3.25 \\
\hline Total & 16.979 & 5.88 \\
\hline & & \\
\hline
\end{tabular}




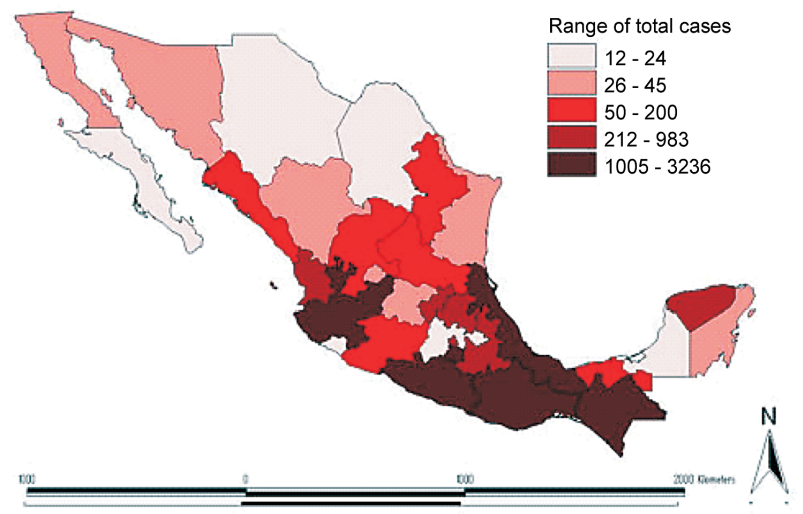

Fig.5: map of Mexico showing the range of total Chagas disease cases detected by serological surveys, clinical manifestations, and cases from blood transfusions.

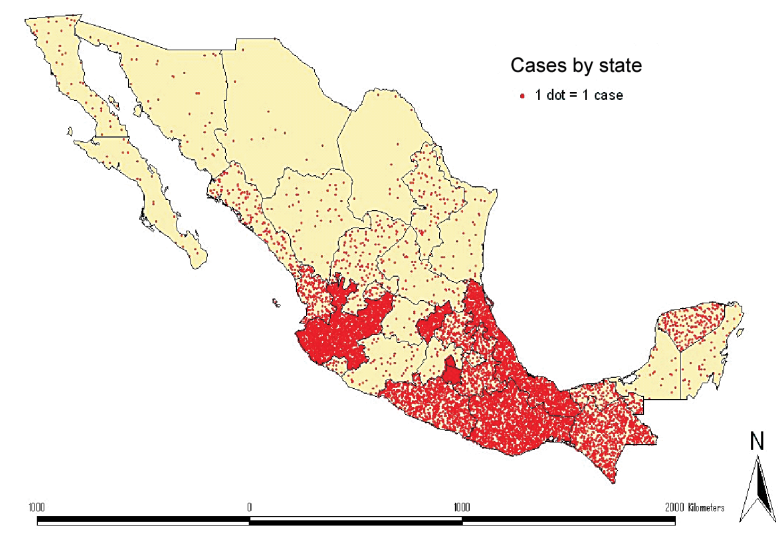

Fig. 6: distribution of all types of Chagas disease in Mexico by state; points represent average density for the state, not the actual locations of each case.

tions, and the year reported can all be queried. For vectors, the species and presence or absence of the parasite is recorded, though some complications arose due to regional and historical variations in the taxonomic classification of the Triatominae. A further drawback is that some of the papers reporting on the presence of vector species did not state whether the insect was positive or negative for $T$. cruzi. For blood bank studies, in 12 out of the 32 states, prevalences are reported on Fig. 7 and Table II.

To better understand the role of geography in the epidemiology of Chagas disease, all papers listed in the database have been assigned a geographic locate. At the broadest level, this geography include also the observation from vectors, and reservoirs (Figs 8, 9, 10). Data attributes with latitude and longitude values were plotted as points in ArcGIS using the Display XY function and were used for more detailed spatial analyses. Point maps were developed for all human cases reported from seroepidemiological surveys, clinical studies and blood transfusion. Also, the nine most important species of vectors of $T$. cruzi and their localities were identified. Having precise geographic locations for this data enables more advanced spatial analysis techniques to be applied. In addition, this data can be used as input for ecological niche

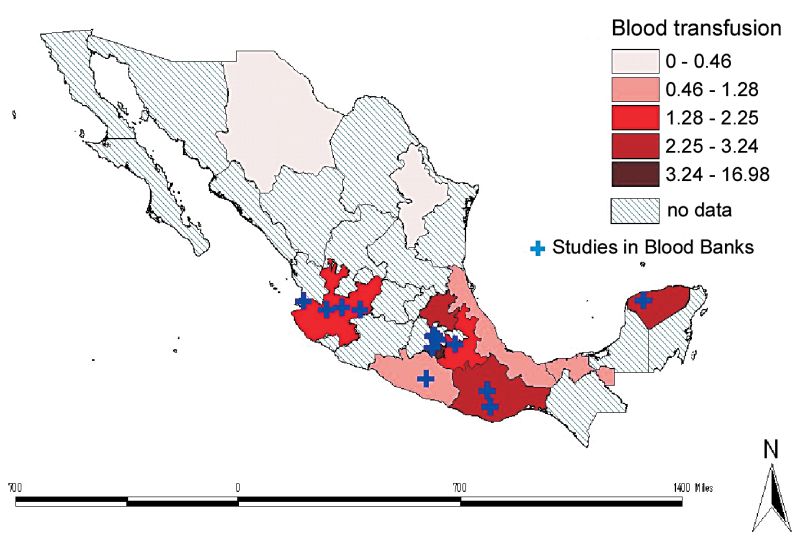

Fig.7: prevalence of positive serology in blood banks, 1978-2004.

TABLE II

Prevalence of positive serology in blood banks by state, 1978-2004

\begin{tabular}{lrrc}
\hline State & Sample & Cases & Prevalence (\%) \\
\hline Chihuahua & 1192 & 2 & 0.17 \\
Distrito Federal & 15.371 & 646 & 4.20 \\
Guerrero & 780 & 10 & 1.28 \\
Hidalgo & 1388 & 45 & 3.24 \\
Jalisco & 4841 & 93 & 1.92 \\
Morelos & 318 & 54 & 16.98 \\
Nuevo Leon & 431 & 2 & 0.46 \\
Oaxaca & 2400 & 69 & 2.88 \\
Puebla & 8656 & 195 & 2.25 \\
Tabasco & 727 & 6 & 0.83 \\
Veracruz & 996 & 11 & 1.10 \\
Yucatan & 2578 & 63 & 2.44 \\
Without georeference & 78.055 & 1192 & 1.53 \\
\hline Total & 117.733 & 2388 & 2.03 \\
\hline
\end{tabular}

modeling techniques such as Desktop GARP or logistic regression (Scachetti-Pereira R, Desktop Garp, Biodiversity Research Center, University of Kansas, US, Center for Information, Campinas, Brazil, http://beta.lifemapper.org/desktopgarp/Default.asp? Item $=1 \& 1 \mathrm{Lanf}=$ 1 ), which rely on primary event data to serve as the inputs for an evolving algorithm that interactively identifies the best environmental and ecological scenarios. The resulting output maps can be used to predict the likely distribution of species, such as vectors or reservoirs of $T$. cruzi. In this study, precise geographic locations were used to create density surfaces, identifying hotspots of distribution of human cases, vectors and reservoirs under investigation (Figs 11, 12, 13).

According to all of the sero-epidemiological sources entered into the database, there have been 16,979 reported human cases of Chagas disease in Mexico.

In only 12 of the 32 Mexican states, have studies been carried out to examine the presence of antibodies against T. cruzi in Public Health Services blood banks, and none have been reported from private hospitals. A total of 117,733 sera have been tested; of those, 2388 were reported positive. 
Without considering subspecies, there are 30 species of triatomines present in Mexico, distributed among seven genera: Belminus, Dipetalogaster, Eratyrus, Paratriatoma, Panstrongylus, Rhodnius, and Triatoma. Based on domiciliary habits and the propensity to def- ecate immediately after a blood meal, 9 of these have been considered important vectors of T. cruzi (Figs 8, 9).

However 21 species have been reported to harbor $T$. cruzi or T. cruzi-like organisms (Table III) (Lent \& Wygodzinsky 1979, Zarate \& Zarate 1985, Vidal-Acosta et al. 2002).

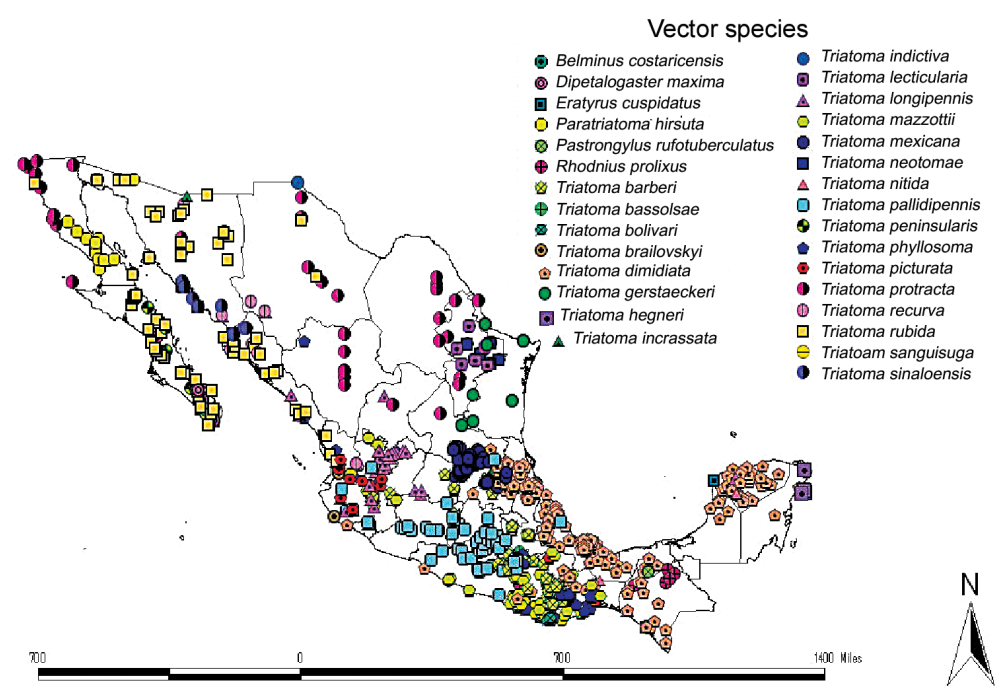

Fig. 8: actual and potential vectors of Trypanosoma cruzi in Mexico.

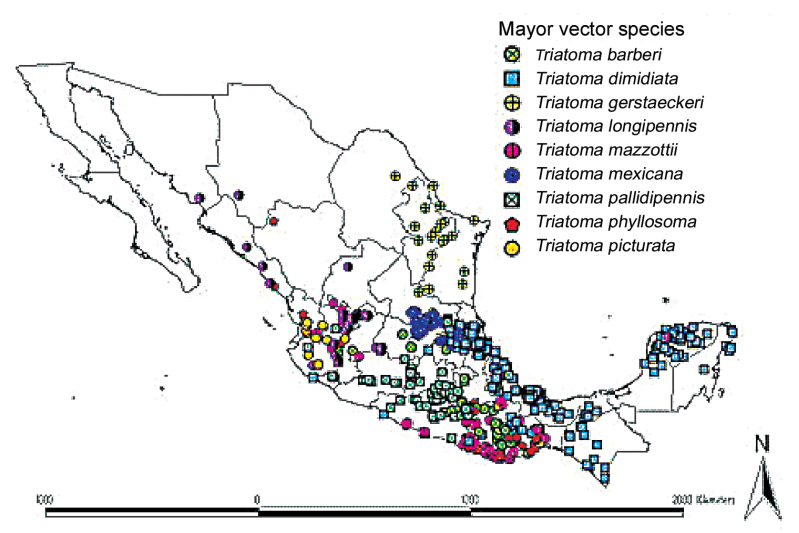

Fig. 9: species of triatomines reported as major vectors in Mexico.

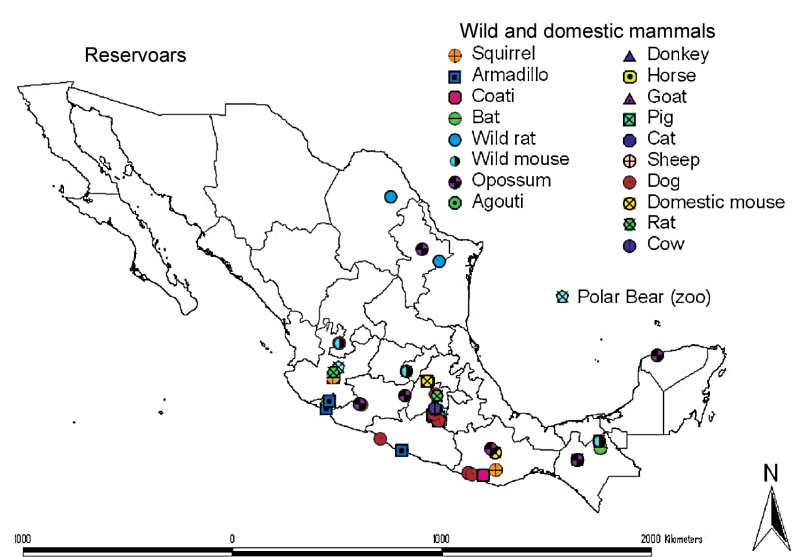

Fig.10: distribution of wild and domestic reservoirs of Trypanosoma cruzi in Mexico.

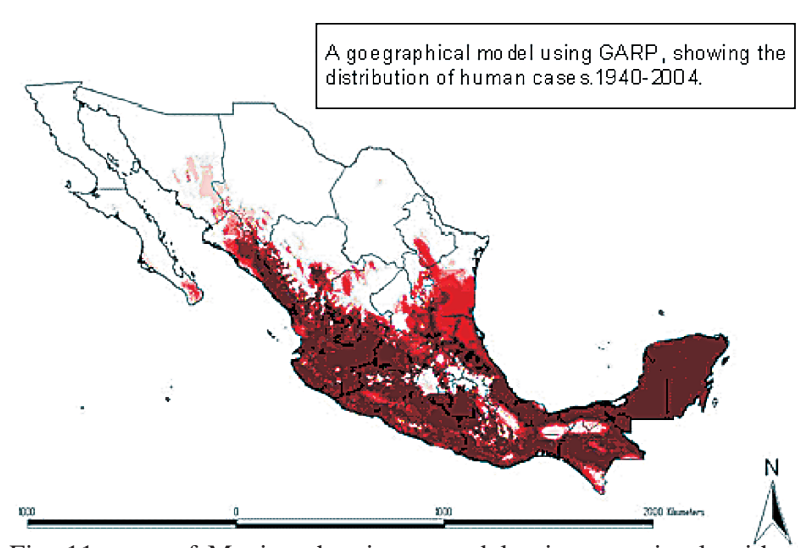

Fig. 11: map of Mexico showing a model using genetic algorithm for rule-Set Prediction (GARP) of distribution of all human cases, based on data from 1940 through 2004.

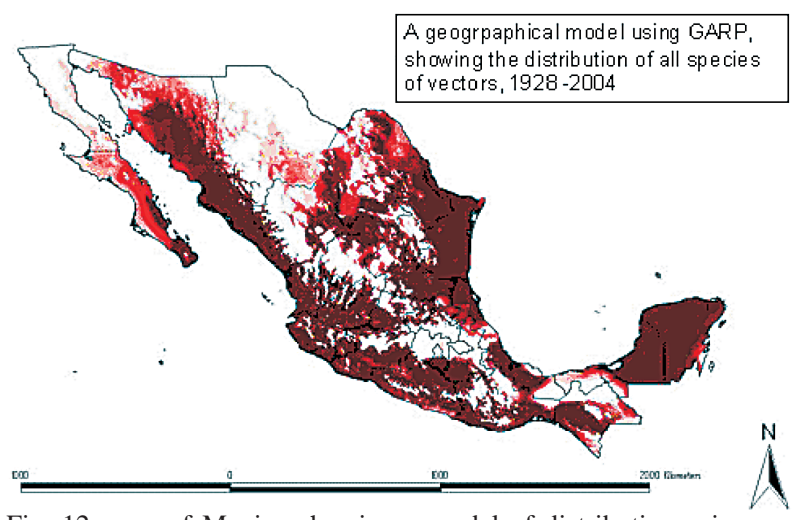

Fig. 12: map of Mexico showing a model of distribution using genetic algorithm for rule-Set Prediction (GARP) for all vector species, 1928 to 2004. 
According to reports from 15 states, there are two major reservoirs, wild (mainly synanthropic), three species of opossums (Didelphis virginiana, D. marsupialis, and Philander opossum); and one domestic, the $\operatorname{dog}(\mathrm{Ca}$ nis familiaris) (Fig. 10).

At least 97 strains have been obtained from three sources: humans, vectors, and reservoirs (domestic and wild) (Table IV).

While there have been several studies using GARP analysis and other techniques for niche modeling, we believe that this is the first time that such techniques have been applied to the whole country (Figs 11, 12, 13).

TABLE III

Mexican triatomines infected* and non infected with Trypanosoma cruzi, by state (different sources)

\begin{tabular}{|c|c|}
\hline State & Species \\
\hline Aguascalientes & Triatoma phyllosoma*; T. longipennis* \\
\hline Baja California Norte & Paratriatoma hirsuta; T. protracta; T. rubida \\
\hline Baja California Sur & Dipetalogaster maxima*; P. hirsuta; T. peninsularis*; T. protracta; T. rubida* \\
\hline Campeche & T. dimidiata* \\
\hline Coahuila & T. gerstaeckeri*; T. protracta* \\
\hline Colima & T. barberi; T. bolivari; T. brailovskyi; T. longipennis; T. pallidipennis*; T. picturata \\
\hline Chiapas & Eratyrus cuspidatus; Pastrongylus rufotuberculatus; Rhodnius prolixus*; T. dimidiata*; T. longipennis* \\
\hline Chihuahua & T. gerstaeckeri; T. indictiva; T. longipennis; T. protracta; T. recurva; T. rubida; T. sanguisuga \\
\hline Distrito Federal & T. barberi; T. pallidipennis \\
\hline Durango & T. phyllosoma; T. protracta* \\
\hline Estado De Mexico & T. incrassata; T. pallidipennis*; T. sanguisuga \\
\hline Guanajuato & T. barberi; T. dimidiata; T. longipennis; T. mexicana*; T. pallidipennis \\
\hline Guerrero & T. barberi*; T. dimidiata*; T. mazzotti*; T. pallidipennis*; T. phyllosoma*; T. recurva*; T. rubida \\
\hline Hidalgo & T. barberi*; T. dimidiata*; T. gerstaeckeri; T. mexicana* \\
\hline Jalisco & $\begin{array}{l}\text { T. barberi }{ }^{*} ; \text { T. bolivari; T. brailovskyi; T. dimidiata*; T. longipennis*; T. mazzottii }{ }^{*} ; \text { T. pallidipennis }{ }^{*} \text {; } \\
\text { T. phyllosoma*; T. picturata*; T. recurva }\end{array}$ \\
\hline Michoacan & T. barberi ${ }^{*} ;$ T. mazzottii ${ }^{*}$; T. pallidipennis $*$; T. recurva \\
\hline Morelos & T, barberi*; T. pallidipennis* \\
\hline Nayarit & $\begin{array}{l}\text { T, bolivari; T. brailovskyi; T. dimidiata; T. longipennis*; T. mazzottii*; T. phyllosoma*; T. picturata*; } \\
\text { T. recurva; T. rubida* }\end{array}$ \\
\hline Nuevo Leon & T. gerstaeckeri ${ }^{*} ;$ T. lecticularia*; T. neotomae*; T. protracta* \\
\hline Oaxaca & $\begin{array}{l}\text { R. prolixus } * \text {, T. barberi }{ }^{*} ; \text { T. bolivari; T. dimidiata*; T. gerstaeckeri }{ }^{*} ; \text { T. longipennis*; }{ }^{*} \text { T. mazzottii*; } \\
\text { T. nitida; T. pallidipennis*; T. phyllosoma*; T. picturata* }\end{array}$ \\
\hline Puebla & T. barberi; T. bassolsae*; T. dimidiata; T. pallidipennis* \\
\hline Queretaro & T. barberi ${ }^{*} ;$ T. mexicana \\
\hline Quintana Roo & T. dimidiata*; T. hegneri* \\
\hline San Luis Potosi & T. dimidiata*; T. gerstaeckeri; T. mexicana; T. pallidipennis ${ }^{*} ;$ T. protracta \\
\hline Sinaloa & $\begin{array}{l}\text { T. indictiva; T. longipennis; T. phyllosoma; T. protracta*; T. recurva*; T. rubida*; T. sanguisuga; } \\
\text { T. sinaloensis* }\end{array}$ \\
\hline Sonora & $\begin{array}{l}\text { P. hirsuta; T. incrassata; T. longipennis*; T. protracta; T. recurva*; T. rubida*; } \\
\text { T. sinaloensis* }\end{array}$ \\
\hline Tabasco & T. dimidiata* \\
\hline Tamaulipas & T. gerstaeckeri*; T. neotomae; T. protracta* \\
\hline Tlaxcala & T. barberi* \\
\hline Veracruz & $\begin{array}{l}\text { Belminus costaricensis; E. cuspidatus; P. rufotuberculatus; T. barberi; T. dimidiata*; T. gerstaeckeri; } \\
\text { T. pallidipennis }\end{array}$ \\
\hline Yucatan & E. cuspidatus; T. dimidiata ${ }^{*} ;$ T. longipennis; T. nitida* \\
\hline Zacatecas & T. longipennis*; T. pallidipennis; T. phyllosoma*; T. protracta \\
\hline
\end{tabular}


TABLE IV

Mexican srtains of Trypanosoma cruzi isolated from different sources

\begin{tabular}{lcccc}
\hline & \multicolumn{3}{c}{ Origin of strains } & \\
\cline { 2 - 4 } State & Human & Vector & Reservoar & Total \\
\hline Aguascalientes & - & 1 & - & 1 \\
Baja California Sur & - & 2 & - & 2 \\
Chiapas & - & 1 & - & 1 \\
Guanajuato & 1 & - & - & 1 \\
Guerrero & 1 & 2 & - & 3 \\
Jalisco & 9 & 13 & - & 22 \\
Michoacan & - & 3 & - & 3 \\
Morelos & 5 & 6 & 3 & 14 \\
Nayarit & - & 2 & - & 2 \\
Nuevo Leon & - & 2 & - & 2 \\
Oaxaca & 6 & 4 & - & 10 \\
Puebla & - & 1 & - & 1 \\
Queretaro & - & 1 & - & 1 \\
Sinaloa & 1 & 1 & - & 2 \\
Sonora & - & 1 & - & 1 \\
Veracruz & 1 & 4 & 6 & 11 \\
Yucatan & 9 & 2 & 5 & 16 \\
Zacatecas & 2 & 2 & - & 4 \\
\hline Total & 35 & 48 & 14 & 97 \\
\hline
\end{tabular}

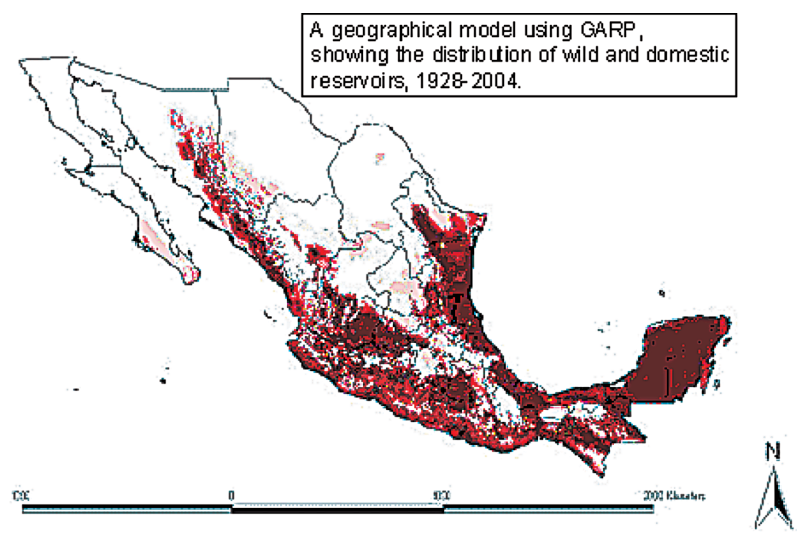

Fig. 13: map of Mexico showing a model of distribution using genetic algorithm for rule-Set Prediction (GARP) of wild and domestic reservoirs, 1928-2004.

All of this information can be checked out in the site: html: Ilwww. unibio.unam. $\mathrm{mx} / \mathrm{chagmex}$

\section{DISCUSSION}

The first report related to Chagas disease in Mexico (Hoffman 1928) was a description of $T$. dimidiata. It was not until 1940 that the first human case was described (Mazzotti 1940), but surprisingly little further information was published on Chagas disease through 1975, since it was considered merely an exotic disease. Only six states and the capital reported any cases during this period. Mostly likely, the presence of this disease in Mexico City is explained largely due to the fact that infected people traveled to the city for the hospitals and former Institute of Tropical Diseases, currently the National Center for Epidemilogical Reference, rather than to actual natural transmission within Mexico City (Biagi \&Arce 1965).

During the later part of the 1970s (1975-1979), new research centers were created to study infectious diseases, including Chagas disease. Even so, there were still few studies published during this period (Godsmith et al. 1979).

The first most productive period, with respect to publications, was 1980-1989. This period was very important, as the research center in Chiapas in the town of San Cristobal de las Casas, (CIES, Centro de Investigaciones Ecologicas del Sureste-Southeast Center for Ecological Investigations), no longer exists. Also, researchers from the University of Yucatan continued describing human cases and new localities where vectors were found (Zarate \& Zarate 1985).

In the early 1990s (1990-1994) interest in Chagas disease research apparently developed, since the number and kind of publications from national and international authors increased dramatically. In different universities from several states, including Mexico City, groups working on Chagas disease were established, while the extant groups were strengthened. Furthermore, at this time, new and diverse disciplines entered into Chagas disease research now not only epidemiological surveys or descriptions of new vector species appeared in the literature, but also molecular biology and genetic studies took over as the traditional subjects. During this period Chiapas remained an object of attention, and two other states, Nayarit and Morelos, became important in terms of the correlation between human cases and the presence of domiciliated vectors. The former, with typical tropical weather, lies $75 \mathrm{~km}$ south of Mexico City and has high economic contrast, in that it is populated by the very rich and the very poor. The increased infection rates are associated with the growing popularity of irregular settlements, particularly surrounding larger towns, with many residents migrating from neighboring states (Puebla, Oaxaca, and Guerrero). The proximity to Mexico City makes Morelos state an ideal region for studying Chagas disease. It is also important to note that the northern states now appear to have more human cases, as well as new records of vectors and wild reservoirs (Tay et al. 1992, AlejandreAguilar et al. 1993, Rangel-Flores et al. 2001).

Two major events during the period, 1995-2004 appeared to influence the data. First, in January 1994, a political problem broke out in Chiapas state where groups of indigenous peoples rebelled against the Federal Government; this conflict is ongoing, dramatically reducing the number of publications, perhaps because of security issues posed when traveling into villages to perform the studies. On the other hand, Jalisco state became the leader in case number, simply because a research group was established at the Univerisdad de Guadalajara in the state capital. Supported, in part, by local health authorities, they performed a survey throughout the state, covering several topics: clinical features (cardiology, gastroenterology), entomology, serology, sociology, and parasitology, but not reservoirs. This situation shows that Chagas disease in Mexico is there to be found when it is looked for (LozanoKasten 1997, Capps \& Begona 2004, Coll-Cardenas et al. 2004). 
Guerrero state also became important as an increasing number of studies were published there. There is a problem in many other states that contributes to the masking of the epidemiological picture of Chagas disease; since many cases are not reported, they remain in the pathology departments as local medical reports in the hospitals, or they are submitted to local journals with very low accessibility, making them difficult to search and obtain (Salgado 1991).

It is evident that $T$. cruzi has always been present in Mexico as well as in the United States (Barr et al. 1991, Hagar \& Rahimtoola 1991, Pung et al. 1995, Herwaldt et al. 2000, Barnabe et al. 2001), the geographic distribution of T. cruzi ranges from the United States to Southern Argentina. According to the information we have compiled about a variety of different topics related to Chagas disease in Mexico, it is clear that we must develop better approaches to understand all of the relevant variables.

Mexico is a country with enormous climatic variety and great biodiversity, providing an opportunity for the development of etiological agents of all kinds. In this, $T$. cruzi is no exception. The invasion of human populations into terrestrial ecosystems has resulted in the establishment and spread of the disease. At least 30 species of triatomines are known and all are potential vectors. Nine or ten of them are recognized as major vectors, but vector capacity and vector competence studies are needed for greater understanding of natural transmission (Zarate \& Zarate 1985 \& Vidal-Acosta et al. 2002).

In addition to role played by insect vectors, numerous species of wild mammals can be reservoirs for $T$. cruzi and their role in the epidemiological chain is not well known (Ruiz-Piña \& Cruz-Reyes 2002) It is widely accepted that opossums and some rodents are some of the best wild reservoirs (Peterson et al. 2002) but domestic also mammals play an important role in the dynamics of the transmission, with dogs being perhaps the most important.

The socioeconomic conditions in many parts of the country are amenable to natural transmission. Many published studies have suggested that sociologic and anthropologic aspects are not taken into account in the prevention of T. cruzi infection and Chagas disease. American trypanosomiasis is a parasitic zoonosis; however, it is not recognized as a major public health problem. As such, there is no infrastructure to establish a regional or national control program.

As stated above, it is hoped that the information discussed in this paper and contained in the CHAGMEX database can be used to reorient the objectives of the medical and biological research communities to maximize the use of economical resources of these research groups around the country. It is also necessary to establish some kind of "national center" to keep, maintain, and control the use of $T$. cruzi strains to assure standard conditions. This will facilitate the generation of more precise information about those Mexican strains that can be used for antigens to develop diagnostic kits to detect infections in Mexican patients (Hernández et al. 2001, Higo et al. 2004).

We believe the geographical approach we have undertaken for the study of Chagas disease will provide in- formation from spatial studies to health authorities that can be used for national programs of control and prevention. However geographical analysis is complicated by the fact that Chagas disease in Mexico, as in many other countries of South America, is no longer exclusively a tropical disease, since it is relatively easy to acquire the infection by blood transfusion, organ transplantation and transplacental transmission (Grant et al. 1989, Kirchhoff 1993, Guzmán-Bracho et al. 1998, Monteón-Padilla et al. 1999, Zayas et al. 2002).

The surveys were performed using different sources of antigens, mainly from Argentina and Brazil, with very few using Mexican antigens, and these only at the research, not commercial level. It is also likely that the technicians running the samples have different skill levels. In Mexico, Jalisco state reported the highest number of cases, 3236.

Unfortunately, the diagnostic tests in blood banks is not carry out in all of them, even when it is an official directive of the Ministry of Health to look for the possible presence of $T$. cruzi antibodies .

There are not standard procedures to isolate, study and keep the strains, some have been studied biologically, biochemically, and genetically; however, there is not "national" bank or center of strains. Could be important to ensure uniformity and guarantee the origin, virulence, or other characteristics of the Mexican strains of T. cruzi. Chagas disease research in Mexico and throughout the world would be greatly facilitated by the establishment of an national or international center for such standard studies.

\section{ACKNOWLEDGEMENTS}

To Jane Margaret Russell from Universidad Nacional Autonoma de México, for her helpfull bibliographic analysis.

\section{REFERENCES}

Alejandre-Aguilar R, Nogueda-Torres B, Calvo Méndez ML, Cotés-Jiménez M 1993. Estudio comparativo de la susceptibilidad de cinco especies de triatominos (Insecta: Reduviidae a la infección con Trypanosoma cruzi. Rev LatAm Microbiol 35: 201-206.

Barnabe Ch, Yaeger R, Pug O, Tibayrenc M 2001 Trypanosoma cruzi: a considerable phylogenetic divergence indicates that the agent of Chagas disease is indigenous to the native fauna of the United States. Exp Parasitol 99: 73-79.

Barr SC, Brown CC, Dennis VA, Kle TR 1991. The lesions and prevalence of Trypanosoma cruzi in opossums and armadillos from southern Louisiana. J Parasitol 77: 624-627.

Biagi F, Arce G 1965. Los dos primeros casos de miocardiopatía chagásica comprobados en México. Arch Inst Cardiol Mexico 35: 611-623.

Capps L, Begona A 2004. Chagas cardiomyopathy and serologic testing in a small rural hospital in Chiapas, Mexico. Pan Amer J Heal 15: 337-340.

Coll-Cardenas R, Espinoza-Gómez F, Maldonado-Rodríguez A, Reyes-López P A, Huerta-Viera M, Rojas-Larios F 2004. Active transmisión of human Chagas desease in Colima Mexico. Mem Inst Oswaldo Cruz 99: 363-368.

Dumontiel E, Gourbière S 2004. Predicting Triatoma dimidiata 
abundance and infection rate: a risk map for natural transmission of Chagas Disease in the Yucatan Peninsula of Mexico. Am J Trop Med Hyg 70: 514-519.

Goldsmith RS, Kagan IG, Zarate R, Reyes-González MA, Cerdeño-Ferreira J 1979. Estudios epidemiológicos de la enfermedad de Chagas en Oaxaca, México. Bol Of Sanit Panam 87: 1-19.

Grant I, Gold J, Wittner M 1989. Transfusion-associated acute Chagas disease acquired in the United States. Ann Inter Med 111: 849-851.

Guzmán-Bracho M del C 2002. Epidemiology of Chagas disease in Mexico: an update 2001. Trends Parasitol 17: 372376.

Guzmán-Bracho M del C, Lahuerta S, Velasco CO 1998. Chagas disease. First congenital case report. Arch Med Res 29: 195196.

Haddock K 1979. Disease and development in the tropics: a review of Chagas disease. Soc Sci Med 13: 53-60.

Hagar J, Rahimtoola S 1991. Chagas disease in the United States. New England J Med 325: 763-768.

Hernández R, Herrera J, Bosseno M F, Breniere S F, Espinoza B 2001. Trypanosoma cruzi: Data supporting clonality in Mexican stocks. J Parasitol 87: 1178-1181.

Herwaldt B L, Grijalva M J, Newsome A L, McGhee C R, Powell, M R, Nemec D G, Steurer F J, Eberhard M L 2000. Use of polymerase chain reaction to diagnose the fifth reported US case of autochthonous transmission of Trypanosoma cruzi, in Tennessee, 1998. J Infect Disea 181: 395399.

Higo H, Miura S, Horio M, Mimori T, Hamano S, Agatsuma T, Yangi T, Cruz-Reyes A, Uyema N, Rojas de Arias A, Matta V, Akahane H, Hirayama K, Takeuchi T, Tada, I, Himeno K 2004. Genotypic variation among linages of Trypanaosoma cruzi and its geographic. Parasitol Inter 53: 337-344.

Hoffman CC 1928. Nota acerca de un probable transmisor de la trypanosomiais humana en el Estado de Veracruz. Rev Mex Biol 8: 12-18.

Johnson LB1999. Analyzing spatial and temporal phenomena using geographical information systems. Land Ecol 4: 3143.

Kirchhoff LV 1993. American trypanosomiasis (Chagas disease) a tropical disease new in the United States. New England J Med 329: 639-644.

Lent H, Wygodzinsky P 1979. Revision of the Triatominae (Hemiptera, Reduviidae), and their significance as vectors of Chagas disease. Bull Amer Mus Nat Hist 163: 125-520.

Lozano-Kasten F, Hernández-Gutiérrez R, Kasten-Monges MJ, Soto-Gutiérrez M, Ramírez-García M A 1997. Manifestaciones digestivas en la fase crónica de la enfermedad de Chagas. Cir Ciruj 65: 10-14.

Mazzotti L 1940.Dos casos humanos de enfermedad de Chagas en el estado de Oaxaca. Gac Med Mexico 70: 417-420.

Monteón-Padilla V M, Hernández-Becerril N, Guzmán-Bracho C, Rosales-Encina J L, Reyes-López P A 1999. American tripanosomiasis (Chagas disease) and blood banking in Mexico City: seroprevalence and its potenctial transfusional transmission risk. Arch Med Res 30: 393-398.
Nogueda-Torres B, Alejandre-Aguilar R, Isita-Tornell L, Camacho AD 2000. Defecation pattern in seven species of Triatomines (Insecta, Reduviidae) presnt in Mexico. Rev Latinoamer Microbiol 145: 145-148.

Norma Oficial Mexicana para la vigilancia epidemiológica, prevención y control de enfermedades transmitidas por vector. In Diario Oficial de la Federación (PROY-NOM-032SSA2-2000) p. 1-45. Enero, 2001.

Ochs D E, Hnilica V S, Moser D R, Smith J H, Kirchhoff L V 1996 Post mortem diagnosis of autochthonous acute chagasic myocarditis by polymerase chain reaction amplification of a species-specific DNA sequence of Typanosoma cruzi. Am J Trop Med Hyg 54: 526-529

Olivier MC, Olivier LJ, Segal DB 1972. A Biblography on Chagas Disease (1909-1969), Index Cat Med Vet Zool Sp. Pub. No. 2, US Goverment Printing Office, Washington $633 \mathrm{pp}$.

Peterson AT, Sánchez-Cordero V, Beard CB, Ramsey JM 2002. Ecological niche modeling and potential reservoirs for Chagas disease, Mexico. Emerg Infect Dise 8: 662-667.

Prothero R, Davenport J 1986. The geography of health in South-East Mexico: A research study and agenda. Soc Sci Med 22: 1321-1327.

Pung OJ, Banks CW, Jones DN, Krissinger MW 1995 Trypanosoma cruzi in wild raccoons, opossums, and triatomine bugs in Southeast Georgia, USA. J Parasitol 81: 324-326.

Rangel H, Gatica R, Ramos C 1998. Detection of antibodies against Trypanosoma cruzi in donors from blood bank in Cuernavaca, Morelos, Mexico. Arch Med Res 29: 79-82.

Rangel-Flores H, Sánchea B, Mendoza-Duarte J, Bernabé C, Breniere F S, Ramos C, Espinoza B 2001. Serologic and parasitologic demonstration of Trypanosoma cruzi infections in an urban area of central Mexico: Correlation with electrocardiographic alterations. Am J Trop Med Hyg 65: 887-895.

Reyes PA, Monteon VM, Hernandez-Becerril N 2002. The risk of transfusion transmission of Chagas disease in Mexico City (Letter to the Editor). Transfusion 40: 613.

Ruiz-Piña H, Cruz-Reyes A 2002. The opossum Didelphis virginiana as a synanthropic reservoir of Trypanosoma cruzi in Dzidzilché, Yucatán, México. Mem Inst Oswaldo Cruz. 97: 613-620.

Salazar-Schettino PM, de Haro-Arteaga I, Ubribarren-Berrueta T 1988. Chagas disease in Mexico. Parasitol Today 4: 348352.

Salgado SP 1991. Estudio seroepidemiologico de la enfermedad de Chagas en el Estado de Guerrero. Ciencia 1: 31-37.

Tay J, Schenone H, Sánchez, JT, Robert L 1992. Estado actual de los conocimientos sobre la enfermedad de Chagas en la República Mexicana. Bol Chileno Parasitol 47: 43-53.

Vidal-Acosta V, Ibañez-Bernal S, Martinez-Campos C 2002 Infección natural de chinches Triatominae con Trypanosoma cruzi asociadas a la vivienda humana en México. Salud Pública de México 42: 496-503.

Walsh, J Molyneux D, Birley H 1993. Deforestation: effects on vector-borne disease. Parasitology 106 (Suppl.): 55-75. 
Zarate LG, Zarate RJ 1985. Checklist of the Triatominae (Hemiptera: Reduviidae) of Mexico. Inter J Epidemiol 27: 102127.

Zavala-Castro JE, Velasco-Castrejón O, Hernández R 1992. Molecular characterization of Mexican stocks of Trypano- soma cruzi using total DNA. Am J Trop Med Hyg 47: 201209.

Zayas CF, Perlino C, Caliendo A, Jackson D, Martes EJ, Tso P, Heffron TG 2002. Chagas disease after organ transplantation - United States, 2001. MMWR 51: 210-212. 